\title{
From Receptors to Ligands: Fragment-assisted Drug Design for GPCRs Applied to the Discovery of H3 and H4 Receptor Antagonists
}

\section{Alexander Heifetz ${ }^{1 *}$, Michael P Mazanetz ${ }^{1}$, Tim James ${ }^{1}$, Sandeep Pal ${ }^{1}$, Richard J Law ${ }^{1}$, Mark Slack ${ }^{2}$ and Philip C Biggin ${ }^{3}$}

${ }^{1}$ Evotec (UK) Ltd., 114 Innovation Drive, Milton Park, Abingdon, Oxfordshire OX14 4RZ, UK

${ }^{2}$ Evotec AG, Manfred Eigen Campus, Essener Bogen 7, 22419 Hamburg, Germany

${ }^{3}$ Department of Biochemistry, University of Oxford, South Parks Road Oxford OX1 3QU, UK

\begin{abstract}
G-Protein Coupled Receptors (GPCRs) have enormous physiological and biomedical importance, being the primary target of a large number of modern drugs. The availability of structural information of the binding site of the targeted GPCR plays a key role in rationalization, efficiency and cost-effectiveness of the drug discovery process. However, obtaining structural information on GPCRs using X-ray crystallography or NMR requires a large investment of time and is technically very challenging. This situation significantly limits the ability of these methods to have an impact in drug discovery for GPCR targets in the short term and hence there is an urgent need for other effective and cost-efficient alternatives. We present here a practical approach that integrates GPCR modelling with fragment based screening to provide structural insights on the $\mathrm{H} 3$ and $\mathrm{H} 4$ histamine receptor binding sites. This approach creates a cost-efficient new avenue for structure-based drug design (SBDD) against GPCR targets. We report here a success of using this protocol for the discovery of selective and dual $\mathrm{H} 3$ and $\mathrm{H} 4$ antagonists. Our fragment screen yielded 44 $\mathrm{H} 3,21 \mathrm{H} 4$ selective and 20 dual fragment hits. These fragments were used to construct high-quality $\mathrm{H} 3$ and $\mathrm{H} 4$ models followed by binding site exploration and structure based virtual screening (VS). Overall, 172 compounds were purchased for testing based on the virtual screening results. Of the 74 compounds predicted to have dual activity, 33 had activity against one or other of the two receptors $(44 \%)$, of which 17 had activity against both. Of the 19 compounds predicted to be $\mathrm{H} 3$ selective, 13 were active against $\mathrm{H} 3(68 \%)$ and 10 of these also had selectivity over $\mathrm{H} 4$. Of the 79 compounds predicted to be $\mathrm{H} 4$ selective, 36 were active against $\mathrm{H} 4(45 \%)$ and 2 of these also had selectivity over $\mathrm{H} 3$.
\end{abstract}

\begin{abstract}
Abbreviations: H3: Histamine 3 Receptor; H4: Histamine 4 Receptor; MD: Molecular Dynamics; FADD: Fragment-Assisted Drug Discovery; SBDD: Structure-Based Drug Discovery; SDM: Site Directed Mutagenesis; FBDD: Fragment-Based Drug Discovery; GPCRs: G-Protein Coupled Receptors; 3D: Three-Dimensional; 7TMD: Seven-Transmembrane Domain; TM: Transmembrane Helix; ECL: Extracellular Loop; ICL: Intracellular Loop; $\beta 2$ AR: B2-Adrenergic Receptor; PDB: Protein Data Bank
\end{abstract}

\section{Introduction}

G-Protein Coupled Receptors (GPCRs) have enormous physiological and biomedical importance, being the primary target of a large number of modern drugs. The availability of structural information on the binding site of the targeted GPCR plays a key role in rationalization, efficiency and cost-effectiveness of the drug discovery process. X-ray crystallography and NMR, the major experimental sources of structural information, are very slow processes for membrane proteins, and are not currently feasible for every GPCR or GPCR-ligand complex. This situation significantly limits the ability of these methods to impact the drug discovery process for GPCR targets in "real-time" and hence there is an urgent need for other practical and cost-efficient alternatives [1]. We present here a practical approach that integrates GPCR modeling with fragment based screening, to provide structural insights on the GPCR binding sites followed by structure based virtual screen (VS).

Fragment-assisted drug discovery (FADD) has emerged as a new tool for drug discovery in recent years $[2,3]$ and is typically aimed at a target for which a crystal structure can be determined in order to rationally guide fragment hit expansion. While the majority of historical fragment screens have been focused towards biochemical targets, only few examples, to date, have been published in which this method has been used to identify ligands for GPCRs [4]. This is due to the current infeasibility of regularly crystallizing the GPCR-fragment complexes that are required for further fragment expansion. Recently, there has been several lines of evidence suggesting that FADD might be useful for GPCR hit identification [5]. These publications encouraged us to try this approach in the discovery of GPCR antagonists.

The $\mathrm{H} 3$ and the $\mathrm{H} 4$ receptor belong to the Class A histamine GPCRs subfamily. The histamine GPCRs signal through Gi/o proteins leading to inhibition of cAMP formation, mobilisation of calcium from intracellular stores and stimulation of MAP kinase in both heterologous expression systems and native immune cells [5,6]. H3 and $\mathrm{H} 4$ receptors remain highly attractive targets for drug discovery and medicinal chemistry development programs [7-10]. While the $\mathrm{H} 3$ receptor seems to be an interesting target for treatment of certain CNS disorders like cognitive disorders, narcolepsy, ADHD and pain $[11,12]$, the $\mathrm{H} 4$ receptor plays an important role inflammation and allergy [13]. Experimental evidence has demonstrated the high therapeutic potential of modulating both the $\mathrm{H} 3$ and $\mathrm{H} 4$ receptors in cancer treatment $[14,15]$.

In the light of this wide clinical evidence of the importance of $\mathrm{H} 3$ and $\mathrm{H} 4$ receptors as potential drug targets [7-10], the need for exploration of the key structural features and key residues involved in antagonist binding and selectivity cannot be overestimated. Such structural data

*Corresponding author: Alexander Heifetz, Evotec (UK) Ltd., 114 Innovation Drive, Milton Park, Abingdon, Oxfordshire OX14 4RZ, UK, Tel: +44 1235 838925; Fax: +44 1235 863139; E-mail: alexander.heifetz@evotec.com

Received November 27, 2013; Accepted December 24, 2013; Published December 27, 2013

Citation: Heifetz A, Mazanetz MP, James T, Pal S, Law RJ, et al. (2013) From Receptors to Ligands: Fragment-assisted Drug Design for GPCRs Applied to the Discovery of $\mathrm{H} 3$ and H4 Receptor Antagonists. Med chem 4: 313-321. doi:10.4172/2161-0444.1000158

Copyright: $\odot 2013$ Heifetz A, et al. This is an open-access article distributed under the terms of the Creative Commons Attribution License, which permits unrestricted use, distribution, and reproduction in any medium, provided the original author and source are credited. 
is vital for driving the development of the next generation of new $\mathrm{H} 3$ or H4 antagonists. Recently several studies were conducted to address this problem, involving in-silico guided site directed mutagenesis data (SDM) [16,17]. This data shows that key residues, responsible for antagonist binding to $\mathrm{H} 3$ receptors are D114 $4^{3.32}, \mathrm{Y} 115^{3.33}, \mathrm{E} 206^{5.45}$ and for $\mathrm{H} 4$ receptors are $\mathrm{D} 94^{3.32}, \mathrm{D} 182^{5.45}$. Mutations of $\mathrm{V}^{3.40} \mathrm{~A}, \mathrm{~N}^{4.57} \mathrm{Y}, \mathrm{T}^{5.42} \mathrm{~A}$, $\mathrm{T}^{6.55} \mathrm{M}$ and $\mathrm{Q}^{7.42} \mathrm{~L}$ showed an average of a $\sim 10$ fold decrease in potency for a series of clobenpropit derivatives (selective $\mathrm{H} 4$ antagonists) to $\mathrm{H} 4$ [18].

In our work, a fragment screen yielded $44 \mathrm{H} 3,21 \mathrm{H} 4$ selective and 20 dual fragment hits. These fragments were used to construct high quality $\mathrm{H} 3$ and $\mathrm{H} 4$ models followed by binding site exploration and structure based VS. Overall, 172 compounds were purchased for testing based on the VS results. Of the 74 compounds predicted to have dual activity, 33 had activity against one or other of the two receptors $(44 \%)$, of which 17 had activity against both. Of the 19 compounds predicted to be $\mathrm{H} 3$ selective, 13 were active against $\mathrm{H} 3(68 \%)$ and 10 of these also had selectivity over $\mathrm{H} 4$. Of the 79 compounds predicted to be $\mathrm{H} 4$ selective, 36 were active against $\mathrm{H} 4$ (45\%) and 2 of these also had selectivity over $\mathrm{H} 3$.

The results reported here are comparable to those from other similar works [19-22] which showed that GPCR modeling [23-31] in the absence of a crystal structure can be a valid replacement [32-39] for structural and functional exploration of GPCR receptors, and for the discovery [21,40-43], VS [44-52] and optimisation [23,53] of their ligands.

\section{Materials and Methods}

\section{Computational methods}

Residue numbering: The position of each amino acid residue of $\mathrm{H} 3$ and $\mathrm{H} 4$ receptors was identified both by its sequence number and by its generic number proposed by Ballesteros and Weinstein for class A GPCRs [54]. Briefly, in this numbering scheme, amino acid residues in the 7 trans-membrane domain (7TMD) are given two numbers; the first corresponds to the trans-membrane helix (TM) number ( 1 to 7), while the second indicates the residue position relative to a highly conserved residue in class A GPCRs in that TM, which is arbitrarily assigned to 50 . The numbering of the loops is done in a similar manner, for example extracellular loop 2 (ECL2) is labeled 45 to indicate its location between helices 4 and 5, and the conserved cysteine (thought to be part of a disulfide-bond) is given the index number 45.50 . The residues within the ECL2 loop are then numbered relative to this position.

\section{$\mathrm{H} 3$ and $\mathrm{H} 4$ modeling procedure}

We performed our hierarchical GPCR modeling protocol [55] in 5 sequential steps: (1) Multiple-Sequence Alignment (2) Template selection (3) Homology Modeling of the receptors (4) Docking procedure and generation of receptor-fragments complex (5) Receptor binding site optimization with "low-mode" molecular dynamics (LowModeMD) simulation.

Multiple-Sequence Alignment is required for selection of the optimum template from the available GPCR crystal structures for further homology modeling of $\mathrm{H} 3$ and $\mathrm{H} 4$. The amino acid sequences of human H3 (UniProtKB/Swiss-Prot ID Q9Y5N1) and human H4 (UniProtKB/Swiss-Prot ID Q9H3N8) were retrieved from the SwissProt database. The sequences of the $\mathrm{H} 3$ and $\mathrm{H} 4$ receptors were aligned with four published GPCR crystal structures [human dopamine D3 receptor (D3, PDB entry $3 \mathrm{PBL}), \beta 2$-adrenergic receptor $(\beta 2 \mathrm{AR}, \mathrm{PDB}$ entry 2RH1), human A2A adenosine receptor (A2A, PDB entry 3EML) and bovine rhodopsin (PDB entry 1F88) - the more recently published crystal structure of the histamine 1 (H1) receptor [56] was not available at the time of this work, using a multiple-sequence alignment tool implemented in MOE version 2010.10 (Chemical Computing Group). In this approach, originally introduced by Needleman in 1970, [57] alignments were computed by optimizing a function based on residue similarity scores obtained from applying an amino acid substitution matrix (blosum62) [58] to pairs of aligned residues and gap penalties. Penalties were imposed for introducing and extending gaps in one sequence with respect to another. The gap start penalty was set at 7 and the penalty for gap extension was set at 1 . The conserved residues and conserved GPCR motifs were constrained to ensure their proper alignment. The position of each amino acid was identified by its sequence number and by the generic number proposed by Ballesteros and Weinstein.

Template selection of the best template for modeling of any GPCR is usually very challenging [37]. Class A GPCRs share the same arrangement of the seven helices [59] and their 7TMD sequence similarities are relatively high [60-63]. However, even small sequence differences can lead to significant differences in overall structure and particularly in the topology of the ligand binding site [64]. This renders each GPCR unique to its exclusive biological function. The most critical sequence difference in GPCRs is the difference in the positions of proline residues [65-67]. Prolines force kinks in TM secondary structure and, as a result, even the smallest difference in the positions of prolines in the sequence alignment of the modeled GPCR and the template can result in a significant decrease in the accuracy of the model [66]. We ranked the quality of crystal structures as potential templates for homology of $\mathrm{H} 3$ and $\mathrm{H} 4$ based on the maximum number of correctly aligned prolines in the 7TMD. The crystal structure that had the highest number of aligned prolines was chosen as a template for further homology modeling.

Homology Modeling of $\mathrm{H} 3$ and $\mathrm{H} 4$ were performed using the homology modeling tool as implemented in the MOE software package (Chemical Computing Group, version 2010.10), based on the template selected in the previous stage. Due to insertions of the $\mathrm{H} 3$ and $\mathrm{H} 4$ sequences with respect to the template, some residues, particularly in the loop regions, did not have assigned backbone geometries based on the template. These insertions were modeled from segments of highresolution chains from the protein data bank (PDB) which superposed well onto anchor residues on each side of the insertion area, after the method described by Fechteler et al. [68]. Following the selection of appropriate loop templates, multiple model candidates for each loop were constructed and scored using the OPLS-AA energy function $[69,70]$. The coordinates of the top ranked loop model were added to the global model. After all of the loops had been added, the side chains were modeled. Sidechain data is assembled from an extensive rotamer library generated by systematic clustering of high- resolution PDB data. After all of the backbone segment and sidechain conformations were chosen, the model was minimized using the MMFF94x force-field [71].

Docking procedure and generation of receptor-fragments complex: In this stage we docked our fragment hits into the binding sites of $\mathrm{H} 3$ and $\mathrm{H} 4$ using a flexible docking procedure. In all docking experiments described in this manuscript we used the GOLD docking package (Cambridge Crystallographic Data Centre, version 5.0), followed by re-scoring and re-ranking procedures. When docking fragments a flexible GOLD docking procedure was used, as fragments were being docked into an unrefined binding site. The rotamer library of GOLD [72] (Cambridge Crystallographic Data Centre) was used to 
add flexibility to the key residues found by SDM. The docking itself was performed once for each molecule, with the 10 top ranked docking poses scored by the GOLD default scoring function [73] retained. We then re-scored and re-ranked these 10 docked poses using AMBER interaction energy. We used the MM-PBSA/GBSA approach [74] to calculate the AMBER interaction energy between protein and ligand. As was recently published $[75,76]$ the AMBER interaction energy, while subject to the same limitations as all force field based methods, was able to accurately predict relative binding affinities between ligand and protein and was therefore selected as a reliable method to re-score and to rank docking poses. The 10 top-ranked docking poses, according to the AMBER interaction energy, was taken for further analysis. The topranked pose of fragments, according to the AMBER interaction energy and SDM, was selected for further binding site refinement.

Receptor binding site optimization: In the final modeling stage, we aimed to optimize the $\mathrm{H} 3$ and $\mathrm{H} 4$ binding sites by applying a "low-mode" molecular dynamics simulation (LowModeMD [77]) to docked fragments pose. The LowModeMD protocol is a stochastic conformation generation protocol implemented in MOE. For the LowModeMD refinement the $\mathrm{H} 3$ and $\mathrm{H} 4$ binding sites were defined by residues within a radius of $7.0 \AA ̊$ of the docked fragments. Flexibility was permitted for all atoms within this radius when the rest of the atoms of $\mathrm{H} 3$ and $\mathrm{H} 4$ and of fragments were restrained. The radius of $7.0 \AA$ was selected to ensure that all the atoms of helical fraction that include close to fragment residues will be also included in refinement. The dielectric constant was set to 3. A LowModeMD constant temperature MD simulation was performed at $300 \mathrm{~K}$, using the Berendsen thermostat [78] and the velocity Verlet algorithm. The default value of the energy minimisation gradient $\left(0.001 \mathrm{kcal} . \mathrm{mol}^{-1} . \AA^{-2}\right)$ was used. The LowModeMD and stochastic searches were terminated after 200 failed attempts to generate a new conformation, with a maximum of 10,000 iterations. To ensure that the TM helices did not "unwind" during the optimization, simple harmonic distance constraints were applied to mimic the $\alpha$-helical i, i +4 carbonyl-amine hydrogen bonds.

\section{Structure-based virtual screen}

We performed structure-based VS in 2 sequential steps: (1) Similarity search followed by (2) Filtering by docking. Figure 1 gives a schematic overview of the strategy that was used starting from GPCR modelling.

Similarity search: We used a shape-pharmacophore superposition method, as it is implemented in OMEGA and ROCS tools of the OpenEye software package (version 3.0.0) [79] to rank the similarity between fragment hits and in-house vendor screening library of $4.8 \mathrm{M}$ compounds. We used OMEGA [80] to generate potential bioactive and energetically accessible conformations for each molecule in the vendor screening library and ROCS for shape-based superposition. A Gaussian description of molecular shape is used to compare the shapes of any two molecules by maximization of their volume intersection [79]. We used docking poses of our fragment hits as templates for superposing with our vendor screening library. Molecules were superposed by a solidbody optimization process that maximizes the overlap volume between them. We used the ROCS default scoring function Combo Score to rank the quantity of the overlap between the fragments and screening library. The Combo Score evaluates the shape and pharmacophore properties (like donor, acceptor, hydrophobe, cation, anion, and ring) overlap between a pair of molecules. It was observed by Hawkins et al. [81] that adding to the shape the score for the appropriate overlap of pharmacophore properties, and then ranking on this summed score, improved VS performance considerably. The top compounds from the screening library, which showed overlap with Combo Score $>1$ to our fragment hits, were selected for further docking and filtering.

Filtering by docking: These top ranked molecules from screening library were docked into the $\mathrm{H} 3$ and $\mathrm{H} 4$ receptors using rigid docking procedure. We used the same docking and scoring protocol as for docking fragments, however no flexibility was allowed for the backbone and sidechains of the receptors. The top ranked compounds according to AMBER interaction energy were manually inspected and selected for binding-functional assays.

\section{Binding and functional assays}

Reagents: Histamine dihydrochloride (53300) was purchased from Fluka, IBMX (410957) was from Calbiochem, HTRF-cAMP dynamic 2 assay kit (62AM4PEB) was from CisBio Bioassays, and FLIPR Calcium 3 Assay Kit, Express (R8108) was from MDS Analytical Technologies. The reference antagonists Thioperamide maleate (0444) and Clobenpropit dihydrobromide (0752) were both purchased from Tocris. HEPES (1 M, 15630-056) and Hanks' Balanced Salt Solution (HBBS 10x, 14065-049) were obtained from Invitrogen while PBS (D8537), Probenecid (P-8761) and Forskolin (F6886) were purchased from Sigma.

Cell lines: The recombinant $\mathrm{CHO}-\mathrm{K} 1$ cell line expressing, Galpha16 with the human H4 (cat no. ES-393-A) and the recombinant CHO-K1 cell line expressing Galpha16 with the human H3 (cat no. ES-393-F) were purchased from Euroscreen (Brussels, Belgium). All cell lines were cultured in Nutrient Mixture F-12 Ham (Sigma, N4888) supplemented with $10 \%$ ( $\mathrm{vol} / \mathrm{vol})$ heat-inactivated fetal calf serum (Sigma, F9665), $100 \mathrm{U} / \mathrm{ml}$ penicillin (PAA, P11- 010), $100 \mu \mathrm{g} / \mathrm{mL}$ streptomycin (PAA, P11-010), $250 \mu \mathrm{g} / \mathrm{ml}$ Zeocin (Invitrogen, R25001), and $500 \mu \mathrm{g} / \mathrm{mL}$ G418 (PAA, P31-011).

Calcium flux assay: The functionality of each histamine receptor was assessed using a standard calcium flux assay and the corresponding stable expressing cell line. Histamine $\mathrm{H} 3$ or $\mathrm{H} 4$ receptor expressing $\mathrm{CHO}-\mathrm{K} 1$ cells (adherent cultures) were seeded into, tissue culturetreated, 384-well, black clear-bottom plates (CellBind Corning 7086); at either $15,000(\mathrm{H} 4)$ or $20,000(\mathrm{H} 3)$ cells/well in culture medium and maintained in an incubator $\left(5 \% \mathrm{CO}_{2}\right.$ at $\left.37^{\circ} \mathrm{C}\right)$ overnight prior to performing the calcium mobilization assays. Cells were washed once with assay buffer (HBSS 1x, $20 \mathrm{mM}$ HEPES pH 7.4) using an automated cell washer leaving the cells in $25 \mu \mathrm{l} /$ well assay buffer. $25 \mu \mathrm{l}$ of the calcium assay kit solution (containing $5 \mathrm{mM}$ probenecid) was added into each well. The final liquid volume before antagonist treatment was

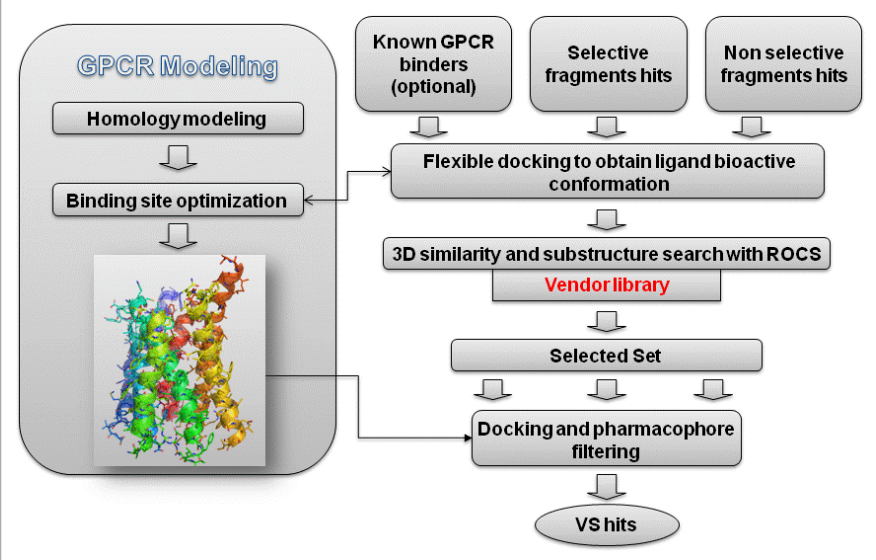

Figure 1: In-silico GPCR workflow used in VS. 
$50 \mu \mathrm{l}$ for all assays. The cell plates were then incubated at $37^{\circ} \mathrm{C}$ for $30 \mathrm{~min}$ prior to addition of $5 \mu \mathrm{l} /$ well of compound solution (freshly diluted in assay buffer from stock solution in DMSO). After $30 \mathrm{~min}$ incubation at $37^{\circ} \mathrm{C} 5 \% \mathrm{CO}_{2}$, the fluorescence intensity was measured on a fluorometric imaging plate reader (FLIPR3; Molecular Devices). The fluorescence intensity before and after the addition of histamine (as agonist) at an $\mathrm{EC}_{80}$ value was measured over 3 minutes.

cAMp HTRF assay protocol: Histamine $\mathrm{H} 3$ or $\mathrm{H} 4$ receptors expressing CHO-K1 cells (adherent cultures) were seeded into, tissue culture-treated, 384-well, white flat bottom plates (Corning 8882) at 10,000 cells/well in culture medium and maintained in an incubator $\left(5 \% \mathrm{CO}_{2}\right.$ at $\left.37^{\circ} \mathrm{C}\right)$ overnight prior to the cAMP assay. For the assay, the medium in the cell plate was manually removed by inverting the plate. $5 \mu \mathrm{L}$ per well of compound solution (freshly diluted in PBS from stock solution in DMSO) was added to cells followed by $5 \mu \mathrm{L}$ per well of histamine at an $\mathrm{EC}_{80}$ in PBS containing IBMX (final concentration: $1 \mathrm{mM}$ ) and forskolin (final concentration: $3 \mu \mathrm{M}$ ). After 30 minutes of incubation at $37^{\circ} \mathrm{C}, 5 \mu \mathrm{L}$ per well of cAMP-d2 lysis buffer was added, followed by $5 \mu \mathrm{L}$ per well of anti-cAMP-cryptate and after an incubation time of $1 \mathrm{~h}$ at RT, the plate was read on EnVision (Excitation: $320 \mathrm{~nm}$; Emission: $615 \mathrm{~nm}$ and $665 \mathrm{~nm}$ ).

\section{Results and Discussion}

\section{Fragments screening}

A collection of five compound plates representing 1,708 fragments from Evotec's fragment library (consisting of 30,000 highly diverse fragments), were screened at 2 and $20 \mu \mathrm{M}$ in the functional calcium flux assays on the $\mathrm{H} 3$ and $\mathrm{H} 4$ receptors to identify antagonists. The compounds were tested at $\mathrm{n}=4$, at each concentration, on each receptor, to provide a rate of confirmed hits. The simultaneous testing on the different receptors allowed an initial assessment of specificity and selectivity of the identified hit compounds. Table 1 summarizes the results of the fragment screening.

The obtained mean Z' values of $0.83(\mathrm{H} 3)$ and $0.59(\mathrm{H} 4)$ indicate a good assay performance. Based on negative sample control wells, thresholds for hit selection between $15 \%$ and $32 \%$ inhibition were calculated. As expected the hit rates were higher at the higher compound concentration whereby the majority of the hits identified at $2 \mu \mathrm{M}$ were also identified at $20 \mu \mathrm{M}$ (see hit overlap). The highest hit rate (64 hits or $3.7 \%$ at $20 \mu \mathrm{M}$ ) was obtained for the $\mathrm{H} 3$ whereas $\mathrm{H} 4$ showed a significantly lower hit rate $(21$ hits or $1.2 \%$ at $20 \mu \mathrm{M})$. Out of $64 \mathrm{H} 3$ fragment hits 20 were dual active and 44 were $\mathrm{H} 3$ selective, whilst all 21 of the $\mathrm{H} 4$ fragment hits were selective. The potency and selectivity of the fragment hits were tested at various concentrations on the three cell lines expressing the histamine receptors $\mathrm{H} 3$ and $\mathrm{H} 4$ in the corresponding calcium flux assays. Finally, our fragment screen yielded $44 \mathrm{H} 3$ selective, $21 \mathrm{H} 4$ selective and 20 dual active hits. Finally our fragment screen yielded $44 \mathrm{H} 3$ selective, $21 \mathrm{H} 4$ selective and 20 dual fragment hits. In Figure 2 we show three examples of these fragment hits that we used to demonstrate our method.

\section{Modelling of human $\mathrm{H} 3$ and $\mathrm{H} 4$ receptors}

The structure of the human $\mathrm{H} 3$ and $\mathrm{H} 4$ receptors were modelled based on a $2.8 \AA$ resolution crystal structure of the $\beta 2$-adrenergic receptor ( $\beta 2 \mathrm{AR}, \mathrm{PDB}$ entry 2RH1 [82]). Multiple sequence alignment, shown in Figure 3, indicated that the $\beta 2 \mathrm{AR}$ had a higher sequence similarity with the $\mathrm{H} 3$ and $\mathrm{H} 4$ receptors compared with other publically-available experimental GPCR structures, with $>52 \%$ sequence similarity within the 7TMD region and 4 aligned prolines for both histamine receptors.

The homology models of $\mathrm{H} 3$ and $\mathrm{H} 3$ are shown in Figure 4A. In spite of the fact that both models shared the same $\beta 2 A R$ template, their final structures were quite different with an RMSD of $>5.7 \AA$ for the 7TMD heavy atoms. This observation can be rationalized by the fact that the overall sequence similarity between these histamine receptors is just $67 \%$. As show in Figure 4B the major differences in 7TMD orientation are observed in TM2, 3 and 4 . In H3, there appeared to be a tilting of these TMs away from their original positions in $\mathrm{H} 4$.

Join to paragraph 6 site of $\mathrm{H} 3$ being longer than in H4, having two extra subpockets $S^{1}$ and $S^{2}$ located between TM2, 3 and $7 \&$ TM3, 4 and 5 respectively. These differences in the binding site topology between $\mathrm{H} 3$ and $\mathrm{H} 4$ are highly important for the design and optimization of selective or dual $\mathrm{H} 3$ and $\mathrm{H} 4$ ligands. For the design of $\mathrm{H} 3$ selective compounds we hypothesize that occupation of the S1 and S2 subpockets is required, and compounds with dual potency would not occupy these subpockets. We also noticed that the conserved $\mathrm{F} 1835.47$ is positioned further inside the $\mathrm{H} 4$ binding site, compared to its position in the $\mathrm{H} 3$ binding site, making it more accessible for interactions with ligands. This observation can help the design of $\mathrm{H} 4$ selective antagonists, as shown previously [2,83-85]. With the models of $\mathrm{H} 3$ and $\mathrm{H} 4$, SDM data and fragment hits in hand, we next turned to the docking, optimization and exploration of receptors binding sites followed by VS.

As outlined above, we used the $\beta 2 \mathrm{AR}$ rather than $\mathrm{H1}$ [56] as a template because a crystal structure of $\mathrm{H} 1$ was not publically available at the time that this work was performed. The use of $\beta 2 \mathrm{AR}$ as a template for modelling of the $\mathrm{H} 3$ and $\mathrm{H} 4$ receptors is widely reported in the literature [86]. A post factum analysis suggest that the $\beta 2 \mathrm{AR}$ is similarly as good as $\mathrm{H} 1$ as a template for the modelling of $\mathrm{H} 3$ and $\mathrm{H} 4$. The sequence identity and similarity between $\beta 2 \mathrm{AR}$ and $\mathrm{H} 3(27 \%$ identity, $52 \%$ similarity) or $\mathrm{H} 4$ (28\% identity, $52 \%$ similarity) receptors are almost identical to those between $\mathrm{H} 1$ and these receptors (H1:H3 $32 \%$ identity, 58\% similarity \& H1:H4 29\% identity, 54\% similarity). As described before [55,87], our modeling method is less dependent on the initial template due to the fact that we apply post homology modeling optimisation procedures. The LowModeMD used by us allowed refinement of the GPCR models to a degree that is not possible with static homology modelling alone [1]. The structural insights gained from this process are critical for the discovery of a new generation of $\mathrm{H} 3$ and $\mathrm{H} 4$ antagonists.

\section{Binding pocket of $\mathrm{H3}$}

The binding site of H3 (Figure 5A) is located between TM3, 5, 6 and

\begin{tabular}{|l|l|l|l|l|}
\hline Number of fragments & H3 & H4 & \\
\hline Concentration & $2 \mu \mathrm{M}$ & $20 \mu \mathrm{M}$ & $2 \mu \mathrm{M}$ & $20 \mu \mathrm{M}$ \\
\hline Compounds & 1708 & 1708 & 1708 & 1708 \\
\hline Mean Z' value & 0.83 & & 0.59 & \\
\hline Hit Threshold & $19.1 \%$ & $16.7 \%$ & $32 \%$ & $31.4 \%$ \\
\hline Confirmed Hits & 19 & 44 & 9 & 21 \\
\hline Selective fragments & 12 & 40 & 3 & 10 \\
\hline Hit Overlap & 17 & & 5 & \\
\hline
\end{tabular}

Table 1: Statistics of fragment screening results.
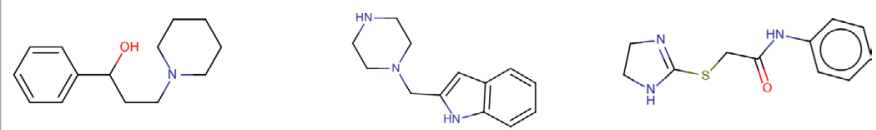

OC-00292-G01 (f1) H3 selective $\mathrm{H} 3 \mathrm{IC}_{50}=530 \mathrm{nM}$ $\mathrm{H} 4 \mathrm{IC}_{50}=$ not active
OC-00296-C07 (f2) $\mathrm{H} 4$ selective $\mathrm{H} 3 \mathrm{IC}_{50}=$ not active $\mathrm{H} 4 \mathrm{IC}_{50}=630 \mathrm{nM}$
OC-00304-D03 (f3) Dual

$\mathrm{H} 3 \mathrm{IC}_{50}=4,300 \mathrm{nM}$ $\mathrm{H} 4 \mathrm{IC}_{50}=4,199 \mathrm{nM}$
Figure 2: Examples of fragment hits used for $\mathrm{H} 3$ and $\mathrm{H} 4$ structure modeling. 
Citation: Heifetz A, Mazanetz MP, James T, Pal S, Law RJ, et al. (2013) From Receptors to Ligands: Fragment-assisted Drug Design for GPCRs Applied to the Discovery of H3 and H4 Receptor Antagonists. Med chem 4: 313-321. doi:10.4172/2161-0444.1000158

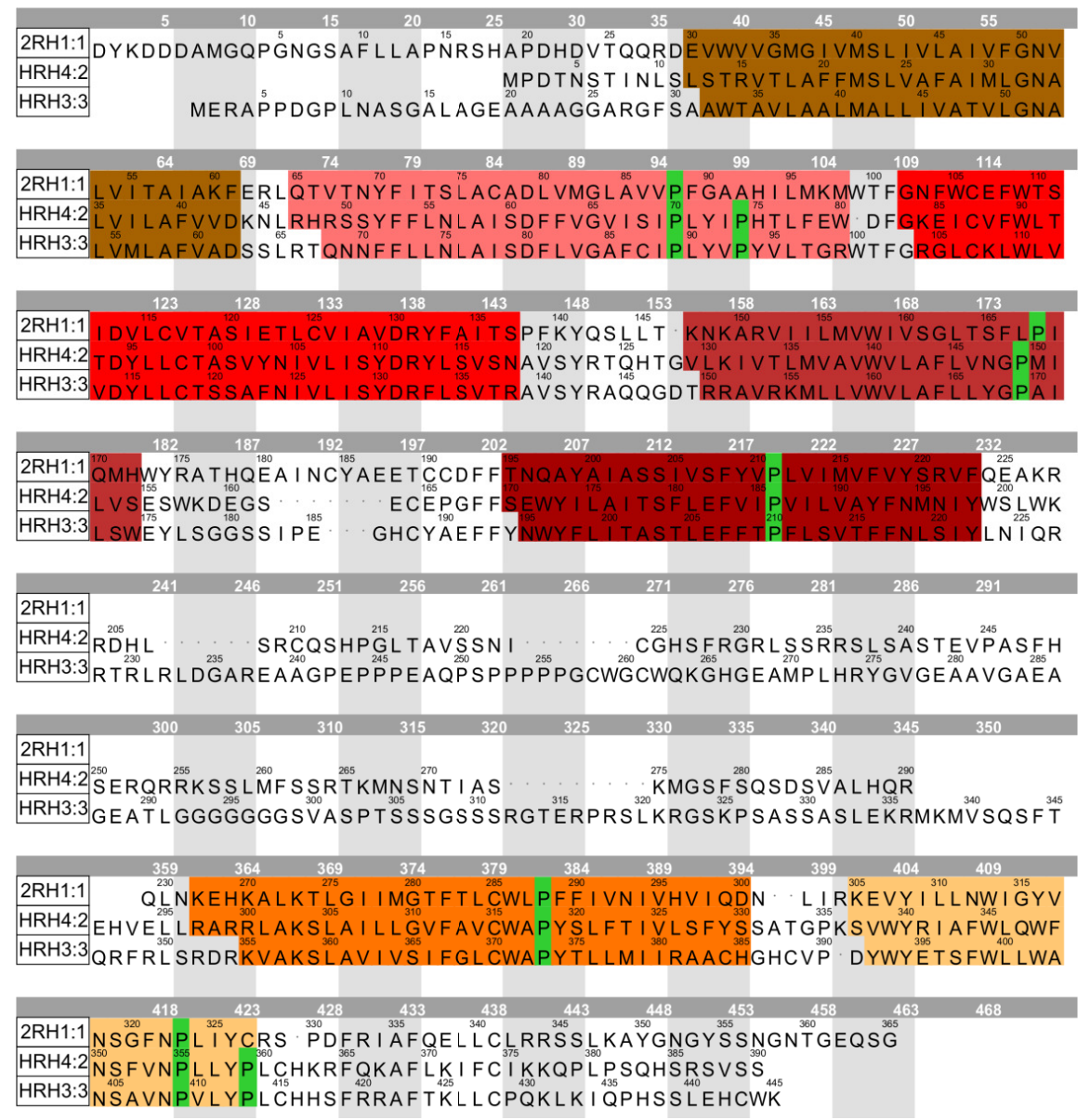

Figure 3: Multiple sequence alignment of $\mathrm{H} 3$ and $\mathrm{H} 4$ receptors aligned with the template ( $\beta 2 \mathrm{AR}, \mathrm{PDB}$ entry $2 \mathrm{RH} 1$ ), the colour coding for TM 1 to 7 is dark orange, pink, red, purple, dark red, orange and light yellow, respectively.

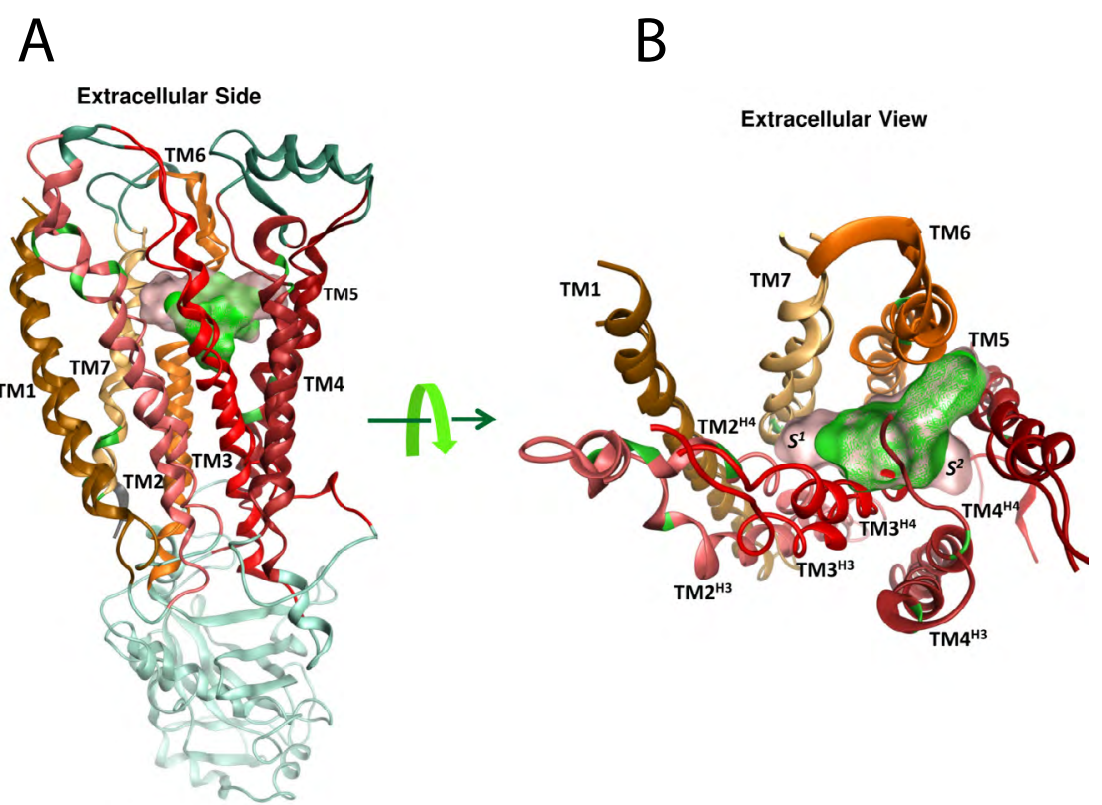

Intracellular Side

Figure 4: $(\mathbf{A})$ and $(\mathbf{B})$ show the final models of $\mathrm{H} 3$ and $\mathrm{H} 4$. The ribbon color coding of TMs 1 to 7 is dark orange, pink, red, purple, dark red, orange and light yellow, respectively, with ICLs and ECLs in dark green and the surface of the receptor binding site in pink for H3 and green for H4. (B) The ICLs and ECLs are omitted to ease the view. 
7. The selective fragment $\mathrm{fl}$ (Figure 2) is predicted to have two distinct binding poses with the $\mathrm{H} 3$ receptor as illustrated in Figure $5 \mathrm{~A}$. In the first docking pose the basic centre of $\mathrm{f} 1$ forms a salt bridge with D114.32 and in the second docking pose, a salt bridge with E206 $6^{5.46}$. In both docking poses the saturated ring of $\mathrm{f} 1$ occupies a hydrophobic subpocket (Figure $4 \mathrm{~B}$ ): in pose 1 it is $\mathrm{S}^{1}$ and in pose 2 it is $\mathrm{S}^{2}$. In the first docking pose the aromatic moiety of $\mathrm{f} 1$ forms a face-to-edger-stacking interaction with W $371^{6.48}$ and in the second docking pose the same moiety forms a face-to-face $\pi$-stacking interaction with W $371^{6.48}$. The interaction with conserved W3716.48 can have a strong impact on the functionality of H3 due to the fact that W6.48 is involved as a"transmission switch". The mechanism and structural changes associated with the functionality of GPCRs remain unclear and many experimental and computational methods have been applied to investigate this $[87,88]$. These methods provided an explanation of receptor functionality based on the action of so-called "molecular switches" buried in the receptor structure. The "transmission switch" accounts for the relocation of conserved residues $\mathrm{W}^{6.48}$ and $\mathrm{F}^{6.44}$ towards $\mathrm{P}^{6.50}$ and is possibly the most common switch among Class A GPCRs. The difference in interaction energies between poses 1 and 2 of $\mathrm{f} 1$ was negligible at $<1.0 \mathrm{kcal} / \mathrm{mol}$, likely due to the fact that in both poses $\mathrm{f} 1 \mathrm{forms}$ two identical types of interaction with $\mathrm{H} 3$ (one salt bridge and one $\pi$-stack). Based on this observation, it was inconclusive which pose was the more likely, and therefore both were used in further VS.

The binding pose of dual fragment $\mathrm{f} 3$ (Figure 2) with $\mathrm{H} 3$ is illustrated in Figure $5 \mathrm{~B}$. The hydrogen donor of the $\mathrm{f} 3$ imidazoline moiety forms a hydrogen bond with D1 $14^{3.32}$ and the hydrogen donor of the $\mathrm{f} 3$ amide linker can potentially form a second hydrogen bond with E206 $6^{5.46}$.

\section{Binding pocket of $\mathrm{H} 4$}

The binding site of H4 (Figure 5C) is located between TM3, 5, 6 and 7. The binding pose of the selective fragment $\mathrm{f} 2$ (Figure 2) with $\mathrm{H} 4$ is illustrated in Figure 5C. The basic centre of $\mathrm{f} 2$ forms a salt bridge with $\mathrm{D} 94^{3.32}$ and the hydrogen donor of the indole core of $\mathrm{f} 2$ forms a hydrogen bond with E1825.46. The indole core of $\mathrm{f} 2$ occupies a hydrophobic subpocket located between TM5 and 6 and forms two face-to-face $\pi$ stacking interactions with $\mathrm{W} 316^{6.48}$ and $\mathrm{F} 183^{5.47}$. As mentioned for $\mathrm{H} 3$ the interaction of $\mathrm{f} 3$ with transmission switch residue $\mathrm{W} 316^{6.48}$ can have a strong impact on the functionality of the $\mathrm{H} 4$ receptor.

The docking pose of the dual fragment f3 (Figure 2) with $\mathrm{H} 4$ is illustrated in Figure 5D. The amide linker hydrogen donor of $\mathrm{f} 3$ forms a hydrogen bond with E182.46, whilst the hydrogen donor of the f3 imidazoline moiety potentially forms a hydrogen bond with $\mathrm{D} 94^{3.32}$. The aromatic moiety of $\mathrm{f} 3$ occupies a hydrophobic subpocket located between TM5 and 6 of the H4 binding site and forms face-to-face $\pi$ stacking interaction with $\mathrm{F} 183^{5.47}$.

\section{Virtual screening}

An in-house vendor screening library of $4.8 \mathrm{M}$ compounds was overlapped with the docking poses of 44 (H3 selective), 21 (H4 selective) and 20 (dual active) fragment hits using the OMEGA and ROCS tools. The ComboScore top ranked 7,500 (H3), 2,000 (H4) and 1,500 (dual) compounds were selected for docking, manual inspection and SDM (pharmacophore) filtering. A total of 172 virtual hits (19 compounds predicted as $\mathrm{H} 3$ selective, 79 as $\mathrm{H} 4$ selective and 74 as dual active) were purchased for further biological testing. While not all of the virtual hits contained the core scaffold of their "parent" fragment, they preserved the pharmacophore, key interactions and other binding features of the original fragment hit. The results and the statistics of the VS are summarized in Table 2.
Overall, 172 compounds were purchased for testing based on the virtual screening results. Of the 74 compounds predicted to have dual activity, 33 had activity against one or other of the two receptors (44\%), of which 17 had activity against both (51\%). Of the 19 compounds predicted to be $\mathrm{H} 3$ selective, 13 were active against $\mathrm{H} 3(68 \%)$ and 10 of these also had selectivity over $\mathrm{H} 4$ (76\%). Of the 79 compounds predicted to be $\mathrm{H} 4$ selective, 36 were active against $\mathrm{H} 4$ (45\%) and 2 of these also had selectivity over $\mathrm{H} 3$ (5\%).

A few examples of $\mathrm{H} 3$ virtual hits are shown in Figure 6A and 6B. The docking pose of $\mathrm{H} 3$ selective virtual hit 29 (Figure 6A) is illustrated in Figure 7A. The basic centre of 29 forms a salt bridge with D114.32 and the aromatic moiety and piperazine ring of 29 form face- to-edge and face-to-face $\pi$-stacking with $\mathrm{W} 371^{6.48}$. The cyclopentane ring of 29 occupies hydrophobic pocket $\mathrm{S}^{1}$ (Figure $4 \mathrm{~B}$ ). The docking pose of the $\mathrm{H} 3$ virtual hit 166 (Figure $6 \mathrm{~B}$ ) is illustrated in Figure 7B. The basic centre of 166 forms a salt bridge with E206 ${ }^{5.46}$, with the benzimidazole core forming hydrogen bond and face-to-face $\pi$-stacking interactions with W371 ${ }^{6.48}$. The hydrogen donor of the 166 benzimidazole core forms a hydrogen bond with D114 ${ }^{3.32}$. The linker of 166 forms hydrophobic contacts with W3716.48

\section{Conclusion}

We present here a practical approach that integrates GPCRmodelling with fragment based screening to provide structural insight into the $\mathrm{H} 3$ and $\mathrm{H} 4$ histamine receptor binding sites, followed by VS. This FADD-modelling approach creates a cost-efficient new avenue for SBDD against GPCR targets. This method extends the boundaries of traditional FBDD where the practicality and cost-efficiency of this approach is enhanced by the generation of structural information on the binding site of a GPCR, to satisfy the immediate need of the

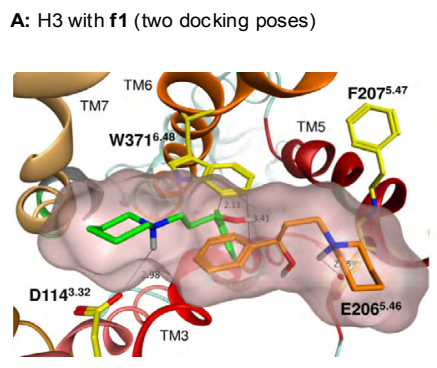

C: $\mathrm{H} 4$ with $\mathbf{f}$

B: $\mathrm{H} 3$ with $\mathbf{f 3}$

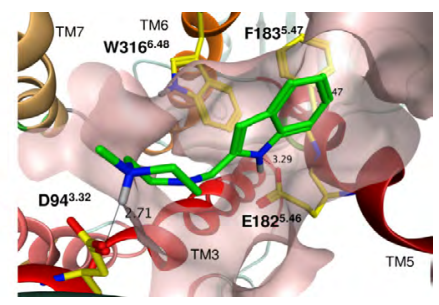

D: $\mathrm{H} 4$ with $\mathbf{f} \mathbf{3}$

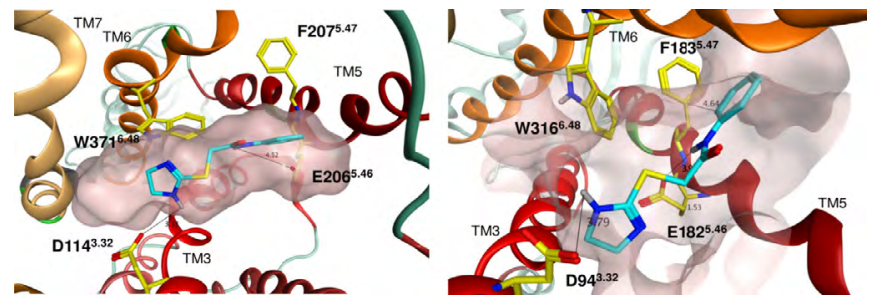

Figure 5: Docked poses of $\mathrm{H} 3$ and $\mathrm{H} 4$ with key fragment hits (A), two distinct docking poses of $\mathbf{f} 1$ in $\mathrm{H} 3$ (B), f3 in $\mathrm{H} 3$ (C), $\mathrm{H} 4$ with $\mathbf{f 2}$ (D), H4 with f3.The ribbon color coding of TMs 1 to 7 is dark orange, pink, red, purple, dark red, orange and light yellow respectively, with ICLs and ECLs in dark green. The ligand carbon atoms are shown in green for $\mathrm{f} 1$ and $\mathrm{f} 2$ ( $A$ and $\mathbf{C}$ ) and cyan for f3 $(B$ and $\mathbf{D})$ and those of the receptors in yellow. Nitrogen atoms are shown in blue, oxygen in red, sulfur in yellow and fluorine in light green. Interactions with key residues are indicated by black dotted lines and the surface of the binding sites are shown in pink and clipped to allow a better view of the four subpockets 


\begin{tabular}{|l|l|l|l|l|}
\hline Receptor & $\begin{array}{l}\text { Number of } \\
\text { VS hits }\end{array}$ & $\begin{array}{l}\text { Number of VS } \\
\text { verified hits }\end{array}$ & $\begin{array}{l}\text { Hit Rate } \\
\text { in \% }\end{array}$ & $\begin{array}{l}\text { Number of selective } \\
\text { hits (Hit Rate^) }\end{array}$ \\
\hline H3 & 19 & 13 & $68 \%$ & $10(76 \%)$ \\
\hline H4 & 79 & 36 & $45 \%$ & $2(5 \%)$ \\
\hline Dual & 74 & 33 (dual) & $44 \%$ (dual) & $17(51 \%)$ \\
\hline
\end{tabular}

*Hits were defined as compounds with $\geq 50 \%$ inhibition at $20 \mu \mathrm{M}$

${ }^{\wedge}$ Percentage of the hits that were also selective or dual active compounds

Table 2: Statistics of VS results.

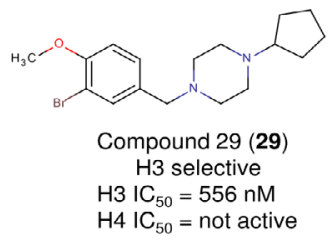

C

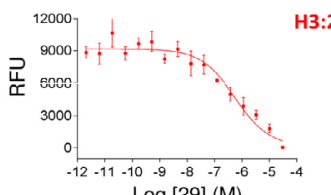

E

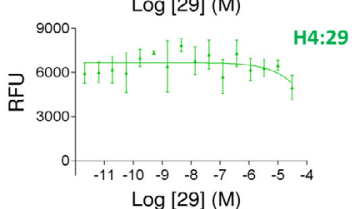

Figure 6: Examples of confirmed virtual hits: (A) $\mathrm{H} 3$, and (B) $\mathrm{H} 4$ selective ligands
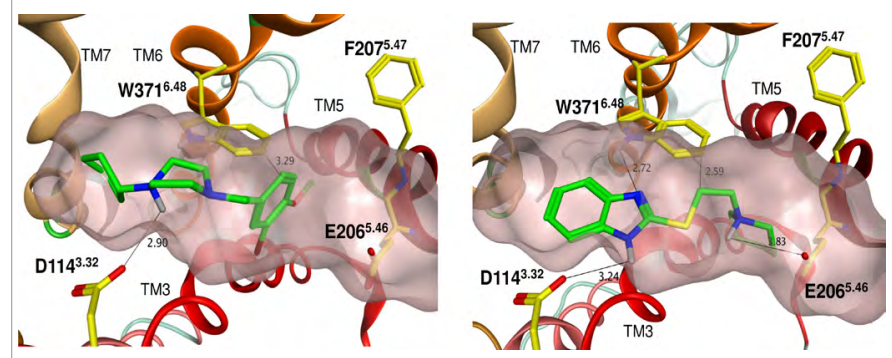

Figure 7: Docked poses of $\mathrm{H} 3$ with the most potent virtual hits $(\mathbf{A})$, docking poses of $\mathrm{H} 3$ with 29 and (B) $\mathrm{H} 3$ with 166. The ribbon color coding of TMs 1 to 7 is dark orange, pink, red, purple, dark red, orange and light yellow, respectively, with ICLs and ECLs in dark green. The ligand carbon atoms are shown in green and those of $\mathrm{H} 3$ in yellow. Nitrogen atoms are shown in blue, oxygen in red, sulfur in yellow and fluorine in light green. Interactions with key residues are indicated by black dotted lines and the surface of the binding sites are shown in pink and clipped to allow a better view of the four subpockets.

drug discovery process for such information. It obviates the need for running an expensive and time consuming HTS. The results presented here are comparable to those from other reports, which demonstrate that GPCR modelling supported by experimental data in the absence of a crystal structure can be a valid replacement for structural and functional exploration of GPCRs and for structure-based drug discovery $[20,22,89-91]$. Feeding the data produced by the primary fragment screen into the GPCR modelling resulted in a considerably higher VS hit rate [2].

Overall, the results show that high quality GPCR modelling can rationally progress a fragment hit to a full size hit. This can be achieved even in the absence of an X-ray crystal structure, as well as then providing a modelling platform for further hit-to-lead investigation. Conventional fragment-based lead generation would typically envisage iterative rounds of fragment expansion through cataloguing combined with medicinal chemistry efforts. In an effort to accelerate and streamline this process, we have successfully achieved hit expansion via the application of VS against an optimized GPCR model, immediately after fragment screening. The identified VS hits themselves can now be used as tools for the further refinement of the existing GPCR models. The LowModeMD simulation protocol used in our work [1,91], followed by flexible docking, has gone beyond the use of static models and allowed for a more detailed exploration of the $\mathrm{H} 3$ and $\mathrm{H} 4$ receptors. The structural insights gained from this process are critical for the discovery of a new generation of $\mathrm{H} 3$ and $\mathrm{H} 4$ antagonists.

\section{Acknowledgement}

We are grateful to Evotec's colleagues Dr. Andreas F. Kahrs, Dr. Orieta Meyn, Dr. Manuela Kluth, Dr. Victoria Martens, Dr. Steffen Köhler, Dr. Giuseppe Gionfriddo, Dr. Jens Andresen, Dr. Pierre llouga, Dr. Christian Kirchhoff, Dr. Helene Ginglinger, Dr. Anna Lena Grecht, Dr. Thomas Hesterkamp, Dr. David Hallet, and Dr. Oliver Barker for helpful discussions and advice.

\section{References}

1. Heifetz A, Barker O, Verquin G, Wimmer N, Meutermans W, et al. (2013) Fighting obesity with a sugar-based library: discovery of novel $\mathrm{MCH}-1 \mathrm{R}$ antagonists by a new computational-VAST approach for exploration of GPCR binding sites. J Chem Inf Model 53: 1084-1099.

2. Sirci F, Istyastono EP, Vischer HF, Kooistra AJ, Nijmeijer S, et al. (2012) Virtual fragment screening: discovery of histamine $\mathrm{H} 3$ receptor ligands using ligandbased and protein-based molecular fingerprints. J Chem Inf Model 52: 33083324.

3. Law R, Barker O, Barker JJ, Hesterkamp T, Godemann R, et al. (2009) The multiple roles of computational chemistry in fragment-based drug design. $J$ Comput Aided Mol Des 23: 459-473.

4. Albert JS, Blomberg N, Breeze AL, Brown AJ, Burrows JN, et al. (2007) An integrated approach to fragment-based lead generation: philosophy, strategy and case studies from AstraZeneca's drug discovery programmes. Curr Top Med Chem 7: 1600-1629.

5. Gbahou F, Vincent L, Humbert-Claude M, Tardivel-Lacombe J, Chabret C, et al. (2006) Compared pharmacology of human histamine $\mathrm{H} 3$ and $\mathrm{H} 4$ receptors: structure-activity relationships of histamine derivatives. $\mathrm{Br} \mathrm{J}$ Pharmacol 147 744-754.

6. Hofstra CL, Desai PJ, Thurmond RL, Fung-Leung WP (2003) Histamine $\mathrm{H} 4$ receptor mediates chemotaxis and calcium mobilization of mast cells. $\mathrm{J}$ Pharmacol Exp Ther 305: 1212-1221.

7. Cole DC, Gross JL, Comery TA, Aschmies S, Hirst WD, et al. Benzimidazoleand indole- substituted 1,3'-bipyrrolidine benzamides as histamine $\mathrm{H} 3$ receptor antagonists. Bioorg. Med Chem Lett 2010: 1237-1240.

8. Letavic MA, Aluisio L, Atack, JR, Bonaventure P, Carruthers, NI, et al. (2010) $\mathrm{J}$ Pre-clinical characterization of aryloxypyridine amides as histamine H3 receptor antagonists: identification of candidates for clinical development Bioorg Med Chem Lett 20: 4210-4214

9. Cramp S, Dyke HJ, Higgs C, Clark DE, Gill M, et al. (2010) Identification and hitto-lead exploration of a novel series of histamine $\mathrm{H} 4$ receptor inverse agonists. Bioorg Med Chem Lett 20: 2516-2519.

10. Engelhardt H, Smits RA, Leurs R, Haaksma E, de Esch IJ (2009) A new generation of anti-histamines: Histamine $\mathrm{H} 4$ receptor antagonists on their way to the clinic. Curr Opin Drug Discov Devel 12: 628-643.

11. Gemkow MJ, Davenport AJ, Harich S, Ellenbroek BA, Cesura A, et al. (2009) The histamine $\mathrm{H} 3$ receptor as a therapeutic drug target for $\mathrm{CNS}$ disorders. Drug Discov Today 14: 509-515.

12. Leurs R, Bakker RA, Timmerman H, de Esch IJ (2005) The histamine H3 receptor: from gene cloning to $\mathrm{H} 3$ receptor drugs. Nat Rev Drug Discov 4: 107120.

13. Thurmond RL, Gelfand EW, Dunford PJ (2008) The role of histamine H1 and $\mathrm{H} 4$ receptors in allergic inflammation: the search for new antihistamines. Nat Rev Drug Discov 7: 41-53.

14. Martinel Lamas DJ, Croci M, Carabajal E, Crescenti EJ, Sambuco L, et al. 
Citation: Heifetz A, Mazanetz MP, James T, Pal S, Law RJ, et al. (2013) From Receptors to Ligands: Fragment-assisted Drug Design for GPCRs Applied to the Discovery of H3 and H4 Receptor Antagonists. Med chem 4: 313-321. doi:10.4172/2161-0444.1000158

(2013) Therapeutic potential of histamine $\mathrm{H}(4)$ receptor agonists in triplenegative human breast cancer experimental model. Br J Pharmacol 170: 188199.

15. Medina V, Croci M, Crescenti E, Mohamad N, Sanchez-Jimenez F, et al. (2008) The role of histamine in human mammary carcinogenesis: $\mathrm{H} 3$ and $\mathrm{H} 4$ receptors as potential therapeutic targets for breast cancer treatment. Cancer Biol Ther 7: 28-35.

16. Shin N, Coates E, Murgolo NJ, Morse KL, Bayne M, et al. (2002) Molecular modeling and site-specific mutagenesis of the histamine-binding site of the histamine $\mathrm{H} 4$ receptor. Mol Pharmacol 62: 38-47.

17. Rai BK, Tawa GJ, Katz A, Humblet H, C. Modeling G protein-coupled receptors for structure-based drug discovery using low-frequency normal modes for refinement of homology models: application to H3 antagonists. Proteins 2010 , $78,457-473$

18. Istyastono EP, Nijmeijer S, Lim HD, van de Stolpe A, Roumen L, et al. Molecular determinants of ligand binding modes in the histamine $\mathrm{H}(4)$ receptor: linking ligand-based three-dimensional quantitative structure-activity relationship (3D-QSAR) models to in silico guided receptor mutagenesis studies. J Med Chem 54: 8136-8147.

19. Congreve M, Langmead C, Marshall FH (2011) The use of GPCR structures in drug design. Adv Pharmacol 62: 1-36.

20. Taylor CM, Rockweiler NB, Liu C, Rikimaru L, Tunemalm AK, et al. (2010) Using ligand-based virtual screening to allosterically stabilize the activated state of a GPCR. Chem Biol Drug Des 75: 325-332.

21. Congreve M, Marshall F (2010) The impact of GPCR structures on pharmacology and structure-based drug design. Br J Pharmacol 159: 986-996.

22. Nikiforovich GV, Marshall GR, Baranski TJ (2008) Modeling molecular mechanisms of binding of the anaphylatoxin $\mathrm{C5a}$ to the $\mathrm{C5a}$ receptor. Biochemistry 47: 3117-3130.

23. Becker OM, Dhanoa DS, Marantz Y, Chen D, Shacham S, et al. (2006) An integrated in silico 3D model-driven discovery of a novel, potent, and selective amidosulfonamide 5-HT1A agonist (PRX-00023) for the treatment of anxiety and depression. J Med Chem 49: 3116-3135.

24. Shacham S, Marantz Y, Bar-Haim S, Kalid O, Warshaviak D, et al. (2004) PREDICT modeling and in-silico screening for G-protein coupled receptors. Proteins 57: 51-86.

25. Becker OM, Marantz Y, Shacham S, Inbal B, Heifetz A, et al. (2004) G proteincoupled receptors: in silico drug discovery in 3D. Proc Natl Acad Sci U S A 101 11304-11309.

26. Goddard WA 3rd, Kim SK, Li Y, Trzaskowski B, Griffith AR, et al. (2010) Predicted 3D structures for adenosine receptors bound to ligands: comparison to the crystal structure. J Struct Biol 170: 10-20.

27. Bray JK, Goddard WA 3rd (2008) The structure of human serotonin 2c G-protein-coupled receptor bound to agonists and antagonists. J Mol Graph Model 27: 66-81.

28. Li Y, Zhu F, Vaidehi N, Goddard WA 3rd, Sheinerman F, et al. (2007) Prediction of the 3D structure and dynamics of human DP G-protein coupled receptor bound to an agonist and an antagonist. J Am Chem Soc 129: 10720-10731.

29. Goddard WA 3rd, Abrol R (2007) 3-Dimensional structures of G proteincoupled receptors and binding sites of agonists and antagonists. J Nutr 137 1528S-1538S

30. Vaidehi N, Schlyer S, Trabanino RJ, Floriano WB, Abrol R, et al. (2006) Predictions of CCR1 chemokine receptor structure and BX 471 antagonis binding followed by experimental validation. J Biol Chem 281: 27613-27620.

31. Vaidehi N, Floriano WB, Trabanino R, Hall SE, Freddolino P, et al. (2002) Prediction of structure and function of $G$ protein-coupled receptors. Proc Nat Acad Sci U S A 99: 12622-12627.

32. Carlsson J, Coleman RG, Setola V, Irwin JJ, Fan H, et al. (2011) Ligand discovery from a dopamine D3 receptor homology model and crystal structure. Nat Chem Biol 7: 769-778.

33. Rayan A (2010) New vistas in GPCR 3D structure prediction. J Mol Model 16: 183-191.

34. Worth CL, Kleinau G, Krause G (2009) Comparative sequence and structura analyses of G-protein-coupled receptor crystal structures and implications for molecular models. PLoS One 4: e7011.
35. Michino M, Abola E; GPCR Dock 2008 participants, Brooks CL 3rd, Dixon JS, Moult J, et al. (2009) Community-wide assessment of GPCR structure modelling and ligand docking: GPCR Dock 2008. Nat Rev Drug Discov 8: 455463.

36. Fanelli F, De Benedetti PG, Raimondi F, Seeber M (2009) Computational modeling of intramolecular and intermolecular communication in GPCRs. Curr Protein Pept Sci 10: 173-185.

37. Fanelli F, De Benedetti PG (2005) Computational modeling approaches to structure-function analysis of $G$ protein-coupled receptors. Chem Rev 105 3297-3351.

38. Katritch V, Abagyan R (2011) GPCR agonist binding revealed by modeling and crystallography. Trends Pharmacol Sci 32: 637-643.

39. Kufareva I, Rueda M, Katritch V, Stevens RC, Abagyan R; GPCR Dock 2010 participants (2011) Status of GPCR modeling and docking as reflected by community-wide GPCR Dock 2010 assessment. Structure 19: 1108-1126.

40. de Graaf C, Rein C, Piwnica D, Giordanetto F, Rognan D (2011) Structurebased discovery of allosteric modulators of two related class B G-proteincoupled receptors. ChemMedChem 6: 2159-2169.

41. Hubbard RE (2011) Structure-based drug discovery and protein targets in the CNS. Neuropharmacology 60: 7-23.

42. Sela I, Golan G, Strajbl M, Rivenzon-Segal D, Bar-Haim S, et al. (2010) G protein coupled receptors -in silico drug discovery and design. Curr Top Med Chem 10: 638-656.

43. Millar RP, Newton CL (2010) The year in G protein-coupled receptor research Mol Endocrinol 24: 261-274.

44. Schneider M, Wolf S, Schlitter J, Gerwert K (2011) The structure of active opsin as a basis for identification of GPCR agonists by dynamic homology modelling and virtual screening assays. FEBS Lett 585: 3587-3592.

45. Sage C, Wang R, Jones G (2011) G-protein coupled receptors virtual screening using genetic algorithm focused chemical space. J Chem Inf Model 51: 17541761.

46. Vilar S, Ferino G, Phatak SS, Berk B, Cavasotto CN, et al. (2011) Docking based virtual screening for ligands of $\mathrm{G}$ protein-coupled receptors: not only crystal structures but also in silico models. J Mol Graph Model 29: 614-623.

47. Jacob L, Hoffmann B, Stoven V, Vert JP (2008) Virtual screening of GPCRs: an in silico chemogenomics approach. BMC Bioinformatics 9: 363.

48. Radestock S, Weil T, Renner S (2008) Homology model-based virtual screening for GPCR ligands using docking and target-biased scoring. J Chem Inf Mode 48: 1104-1117.

49. Engel S, Skoumbourdis AP, Childress J, Neumann S, Deschamps JR, et al. (2008) A virtual screen for diverse ligands: discovery of selective $G$ proteincoupled receptor antagonists. J Am Chem Soc 130: 5115-5123.

50. Cavasotto CN, Orry AJ, Murgolo NJ, Czarniecki MF, Kocsi SA, et al. (2008) Discovery of novel chemotypes to a G- protein-coupled receptor through ligand-steered homology modeling and structure-based virtual screening. $J$ Med Chem 51: 581-588.

51. Chen JZ, Wang J, Xie XQ (2007) GPCR structure-based virtual screening approach for CB2 antagonist search. J Chem Inf Model 47: 1626-1637.

52. Evers A, Klabunde T (2005) Structure-based drug discovery using GPCR homology modeling: successful virtual screening for antagonists of the alpha1 $\mathrm{A}$ adrenergic receptor. J Med Chem 48: 1088-1097.

53. Tautermann CS (2011) The use of G-protein coupled receptor models in lead optimization. Future Med Chem 3: 709-721.

54. Ballesteros JA, Weinstein $H$ (1995) Integrated methods for construction three dimensional models and computational probing of structure-function relations in $\mathrm{G}$ protein-coupled receptors. Methods Neurosci 25: 366-428.

55. Heifetz A, Morris GB, Biggin PC, Barker O, Fryatt T, et al. (2012) Study of human Orexin-1 and -2 G-protein-coupled receptors with novel and published antagonists by modeling, molecular dynamics simulations, and site-directed mutagenesis. Biochemistry 51: 3178-3197.

56. Shimamura T, Shiroishi M, Weyand S, Tsujimoto H, Winter G, et al. (2011) Structure of the human histamine $\mathrm{H} 1$ receptor complex with doxepin. Nature 475: 65-70.

57. Needleman SB, Wunsch CD (1970) A general method applicable to the search for similarities in the amino acid sequence of two proteins. J Mol Biol 48: 443453. 
Citation: Heifetz A, Mazanetz MP, James T, Pal S, Law RJ, et al. (2013) From Receptors to Ligands: Fragment-assisted Drug Design for GPCRs Applied to the Discovery of H3 and H4 Receptor Antagonists. Med chem 4: 313-321. doi:10.4172/2161-0444.1000158

58. Styczynski MP, Jensen KL, Rigoutsos I, Stephanopoulos G (2008) BLOSUM62 miscalculations improve search performance. Nat Biotechnol 26: 274-275.

59. Baldwin JM (1993) The probable arrangement of the helices in G proteincoupled receptors. EMBO J 12: 1693-1703.

60. Cobanoglu MC, Saygin Y, Sezerman U (2011) Classification of GPCRs using family specific motifs. IEEE/ACM Trans Comput Biol Bioinform 8: 1495-1508.

61. Gloriam DE, Foord SM, Blaney FE, Garland SL (2009) Definition of the G protein-coupled receptor transmembrane bundle binding pocket and calculation of receptor similarities for drug design. J Med Chem 52: 4429-4442.

62. Gao QB, Wang ZZ (2006) Classification of G-protein coupled receptors at four levels. Protein Eng Des Sel 19: 511-516.

63. Wistrand M, Kall L, Sonnhammer EL (2006) A general model of G proteincoupled receptor sequences and its application to detect remote homologs. Protein Sci 15: 509-521.

64. Bettinelli I, Graziani D, Marconi C, Pedretti A, Vistoli G (2011) The approach of conformational chimeras to model the role of proline-containing helices on GPCR mobility: the fertile case of Cys-LTR1. ChemMedChem 6: 1217-1227.

65. Langelaan DN, Wieczorek M, Blouin C, Rainey JK (2010) Improved helix and kink characterization in membrane proteins allows evaluation of kink sequence predictors. J Chem Inf Model 50: 2213-2220.

66. Hall SE, Roberts K, Vaidehi N (2009) Position of helical kinks in membrane protein crystal structures and the accuracy of computational prediction. $\mathrm{J} \mathrm{Mol}$ Graph Model 27: 944-950.

67. Yohannan S, Faham S, Yang D, Whitelegge JP, Bowie JU (2004) The evolution of transmembrane helix kinks and the structural diversity of $G$ protein-coupled receptors. Proc Natl Acad Sci U S A 101: 959-963.

68. Fechteler T, Dengler U, Schomburg D (1995) Prediction of protein threedimensional structures in insertion and deletion regions: a procedure for searching data bases of representative protein fragments using geometric scoring criteria. J Mol Biol 253: 114-131.

69. Jorgensen W, Maxwell LDS, Tirado RJ (1996) Development and testing of the OPLS all-atom force field on conformational energetics and properties of organic liquids. J Am Chem Soc 118: 11225-11236.

70. Kaminski GA, Friesner J, Tirado RJ, Jorgensen W (2001) Evaluation and reparameterization of the OPLS-AA force field for proteins via comparison with accurate quantum chemical calculations on peptides. J Phys Chem B 105: 6474-6487.

71. Courcot B, Bridgeman AJ (2011) Modeling the interactions between polyoxometalates and their environment. J Comput Chem 32: 3143-3153.

72. Jones G, Willett $P$, Glen RC (1995) Molecular recognition of receptor sites using a genetic algorithm with a description of desolvation. J Mol Biol 245: 43-53.

73. Liebeschuetz JW, Cole JC, Korb O (2012) Pose prediction and virtual screening performance of GOLD scoring functions in a standardized test. J Comput Aided Mol Des 26: 737-748.

74. Kollman PA, Massova I, Reyes C, Kuhn B, Huo S, et al. (2000) Calculating structures and free energies of complex molecules: combining molecular mechanics and continuum models. Acc Chem Res 33: 889-897.
75. Homeyer N, Gohlke H (2013) FEW: a workflow tool for free energy calculations of ligand binding. J Comput Chem 34: 965-973.

76. Hoffer L, Horvath D (2013) S4MPLE--sampler for multiple protein-ligand entities: simultaneous docking of several entities. J Chem Inf Model 53: 88-102.

77. Labute $P$ (2010) LowModeMD--implicit low-mode velocity filtering applied to conformational search of macrocycles and protein loops. J Chem Inf Model 50: 792-800.

78. Berensden HJC, Postma JPM, Van-Gunsteren WF, DiNola A, Haak JR (1984) Molecular-Dynamics with Coupling to an External Bath. J Chem Phys 81: $3684-$ 3690 .

79. Grant JA, Pickup BT, Sykes MJ, Kitchen CA, Nicholls A (2007) The Gaussian Generalized Born model: application to small molecules. Phys Chem Chem Phys 9: 4913-4922.

80. Hawkins PC, Nicholls A (2012) Conformer generation with OMEGA: learning from the data set and the analysis of failures. J Chem Inf Model 52: 2919-2936.

81. Hawkins PC, Skillman AG, Nicholls A (2007) Comparison of shape-matching and docking as virtual screening tools. J Med Chem 50: 74-82.

82. Rasmussen SG, Choi HJ, Rosenbaum DM, Kobilka TS, Thian FS, et al. (2007) Crystal structure of the human beta2 adrenergic G-protein-coupled receptor. Nature 450: 383-387.

83. Istyastono EP, de Graaf C, de Esch IJ, Leurs R (2011) Molecular determinants of selective agonist and antagonist binding to the histamine Hâ,,, receptor. Curr Top Med Chem 11: 661-679.

84. Smits RA, Adami M, Istyastono EP, Zuiderveld OP, van Dam CM, et al. (2010) Synthesis and QSAR of quinazoline sulfonamides as highly potent human histamine H4 receptor inverse agonists. J Med Chem 53: 2390-2400.

85. Lim HD, de Graaf C, Jiang W, Sadek P, McGovern PM, et al. (2010) Molecular determinants of ligand binding to H4R species variants. Mol Pharmacol 77 : 734-743.

86. Wijtmans M, de GC, de KG, Istyastono EP, Smit J, et al. (2011) Triazole ligands reveal distinct molecular features that induce histamine $\mathrm{H} 4$ receptor affinity and subtly govern H4/H3 subtype selectivity. J Med Chem 54: 1693-1703.

87. Farrens DL, Altenbach C, Yang K, Hubbell WL, Khorana HG (1996) Requirement of rigid-body motion of transmembrane helices for light activation of rhodopsin. Science 274: 768-770.

88. Gether U, Lin S, Ghanouni P, Ballesteros JA, Weinstein H, et al. (1997) Agonists induce conformational changes in transmembrane domains III and VI of the beta2 adrenoceptor. EMBO J 16: 6737-6747.

89. Shoichet BK, Kobilka BK (2012) Structure-based drug screening for G-proteincoupled receptors. Trends Pharmacol Sci 33: 268-272.

90. Congreve M, Langmead CJ, Mason JS, Marshall FH (2011) Progress in structure based drug design for $\mathrm{G}$ protein-coupled receptors. J Med Chem 54: 4283-4311.

91. Heifetz A, Barker O, Morris GB, Law RJ, Slack M, et al. (2013) Toward an understanding of agonist binding to human orexin-1 and orexin-2 receptors with g-protein-coupled receptor modeling and site-directed mutagenesis. Biochemistry 52: 8246-8260. 